\title{
Perbandingan Peningkatan Laju Nadi dan MAP antara Laringoskopi Menggunakan Bilah Laringoskop Macintosh dan McCoy
}

\author{
Andy Hutariyus, ${ }^{1}$ Iwan Fuadi, ${ }^{2}$ Dewi Yulianti Bisri ${ }^{2}$ \\ ${ }^{1}$ Rumah Sakit Umum Mattaher Prov. Jambi, ${ }^{2}$ Departemen Anestesiologi dan Terapi Intensif \\ Fakultas Kedokteran Universitas Padjadjaran/RSUP Dr. Hasan Sadikin Bandung
}

\begin{abstract}
Abstrak
Tindakan laringoskopi dan intubasi dapat menyebabkan peningkatan kadar katekolamin di dalam darah sehingga meningkatkan respons hemodinamik seperti takikardia, peningkatan tekanan darah, peningkatan tekanan intrakranial, aritmia, dan perubahan segmen ST. Respons ini bergantung pada seberapa banyak manipulasi di daerah lidah, faring, laring, dan epiglotis pada saat laringoskopi direk. Tujuan penelitian ini membandingkan peningkatan laju nadi dan mean arterial pressure (MAP) antara laringoskopi intubasi menggunakan bilah Macintosh dan McCoy. Metode penelitian ini adalah uji klinis acak terkontrol buta tunggal pada 40 pasien yang menjalani operasi dengan anestesi umum di RSUP Dr. Hasan Sadikin Bandung dari bulan Juli hingga Agustus 2018. Subjek penelitian dibagi menjadi dua kelompok, kelompok MI laringoskopi intubasi dengan Macintosh dan kelompok MC laringoskopi intubasi dengan McCoy. Data hasil penelitian diuji secara statistik menggunakan uji t tidak berpasangan dan Uji Mann-Whitney. Hasil penelitian ini menunjukkan perbedaan laju nadi dan MAP setelah intubasi pada kelompok McCoy lebih rendah dibanding dengan Macintosh pada menit ke-1, menit ke-2,5, dan menit ke-5 dengan perbedaan signifikan $(p<0,05)$. Simpulan penelitian ini menunjukkan bahwa laringoskopi dengan bilah laringoscop McCoy dapat mengurangi peningkatan laju nadi dan MAP dibanding dengan Macintosh.
\end{abstract}

Kata kunci: Bilah laringoskop Macintosh, bilah laringoskop McCoy, laju nadi, tekanan darah

\section{Comparison between Laryngoscopy Using Macintosh and McCoy Laryngoscope Blades in Increasing Heart Rate and Mean Arterial Pressure}

\begin{abstract}
Laryngoscopy and intubation often increase hemodynamic responses such as tachycardia, increased blood pressure, increased intracranial pressure, arrhythmia, and changes on the ST segment due to increased blood catecholamines. This response depends on how much the tongue, pharynx, larynx, and epiglottis are manipulated during a direct laryngoscopy. This study was a single blinded randomized controlled trial on 40 patients who underwent surgery under general anesthesia in Dr. Hasan Sadikin General Hospital from July to August 2018. Subjects of study were randomly divided into two groups, Macintosh (MI) and McCoy (MC) groups. Data were analyzed using t-test and Mann-Whitney test. Results of this study found that lower heart rate and MAP increases were identified in McCoy group when compared to the Macintosh group in minute 1 , minute 2,5 , and minute 5 after intubation. Both variables had statistically significant differences $(\mathrm{p}<0.05)$. This study concludes that laryngoscopy using McCoy laryngoscope blade was is able to prevent increase in heart rate and MAP compared to Macintosh.
\end{abstract}

Key words: Blood pressure, heart rate, Macintosh laryngoscope blade, McCoy laryngoscope blade

Korespondensi: Andy Hutariyus, dr., SpAn, Rumah Sakit Umum Mattaher Prov. Jambi, Jl. Letjend Soeprapto No. 31, Telanai pura, Jambi, Tlpn (0741) 61692,Email hutariyus_andy@yahoo.com 


\section{Pendahuluan}

Penanganan jalan napas merupakan tindakan rutin yang dilakukan oleh dokter anestesi. ${ }^{1,2}$ Intubasi endotrakea dengan laringoskopi direk merupakan prosedur standar untuk proteksi jalan napas dari risiko aspirasi, penggunaan bantuan ventilasi mekanik, dan dilakukan pada prosedur operasi dengan cara anestesi umum. ${ }^{3}$ Bilah Macintosh merupakan pilihan utama pada pasien dewasa karena bentuk yang melengkung sehingga memudahkan ujung bilah masuk ke dalam valekula dan dapat menyingkirkan lidah secara aman. ${ }^{2,4}$

Jalan napas atas manusia banyak dipersarafi oleh saraf sensorik berasal dari percabangan saraf kranialis glossopharyngeal dan saraf vagus dan juga mengandung proprioceptors yang dapat menimbulkan stimulus noxius. ${ }^{5,6}$ Rangsang simpatis saat laringoskopi dan intubasi diakibatkan manipulasi mulai dari mukosa lidah, palatum, epiglotis, faring, dan laring. ${ }^{7}$ Tindakan laringoskopi dan intubasi menyebabkan peningkatan kadar katekolamin di dalam darah dan blokade beta adrenergik sehingga menyebabkan lonjakan hemodinamik seperti takikardia, peningkatan tekanan darah, peningkatan tekanan intrakranial, aritmia, dan perubahan segmen ST. ${ }^{8,9}$ Respons ini ditentukan oleh seberapa banyak manipulasi di derah lidah, epiglotis, faring, dan laring pada saat tindakan laringoskopi direk. ${ }^{3,7}$

Pencegahan terjadi lonjakan hemodinamik pada saat laringoskopi dan intubasi dapat dilakukan dengan metode farmakologi dan nonfarmakologi. ${ }^{5,10}$ Penelitian tentang metode farmakologi untuk mencegah lonjakan respons hemodinamik saat laringoskopi intubasi sudah banyak dilakukan menggunakan obat-obatan seperti anestesi lokal (lidokain), opioid, obat penghambat adrenergik (baik yang bekerja pada reseptor alfa maupun beta), vasodilator seperti hidralazin, natrium nitroprusid, nitrogliserin, juga obat anestesi intravena ataupun inhalasi. ${ }^{11,12}$ Penelitian metode nonfarmakologi dengan menggunakan teknik dan alat intubasi seperti fiber optic, glidescope, dan McCoy terbukti efektif untuk mencegah lonjakan hemodinamik pada saat laringoskopi dan intubasi. ${ }^{1,2,10}$ Keadaan ini karena kontak yang minimal dengan jalan napas atas saat laringoskopi dan dapat menghasilkan derajat Cormack and Lehane yang lebih baik dengan manuver jalan napas yang minimal. ${ }^{1,12}$

Penelitian dengan metode nonfarmakologi untuk mencegah terjadi lonjakan hemodinamik saat laringoskopi intubasi belum banyak dilaksanakan. 5,12,13 Beberapa penelitian yang sebelumnya menunjukkan bahwa pemilihan laringoskop dapat memengaruhi kondisi hemodinamik pada pasien pascatindakan laringoskopi intubasi endotrakea. ${ }^{4,14}$ Secara teoritis pemilihan alat laringoskopi dengan kontak dan manipulasi yang minimal dapat mengurangi lonjakan hemodinamik., ${ }^{3,4}$ Laporan penelitian telah banyak membuktikan teori ini, namun ada pula penelitian yang menunjukkan bahwa perbedaan penggunaan kedua jenis laringoskop ini tidak signifikan. ${ }^{2}$

Penelitian ini bertujuan membandingkan peningkatan laju nadi dan MAP antara laringoskopi intubasi mempergunakan bilah laringoskop Macintosh dan McCoy pada pasien yang menjalani operasi dengan anestesi umum.

\section{Subjek dan Metode}

Penelitian ini adalah penelitian eksperimental dengan uji klinis rancangan acak terkontrol buta tunggal atau single blind randomized controlled trial. Subjek penelitian adalah pasien yang dilakukan operasi elektif dengan anestesi umum di Rumah Sakit Umum Pusat Dr. Hasan Sadikin Bandung pada bulan Juli hingga Agustus 2018. Kriteria inklusi adalah pasien yang dilakukan anestesi umum dengan intubasi orotrakea, status fisik American Society of Anesthesiology (ASA) I, usia 18-45 tahun, buka mulut lebih dari $3 \mathrm{~cm}$, mallampati 1 dan 2, thyromental distance lebih dari 5 $\mathrm{cm}$, dan tidak ada keterbatasan gerak leher. Kriteria eksklusi meliputi operasi pada daerah intraoral, kepala atau leher, dan body mass index (BMI) lebih dari 30. Kriteria pengeluaran, yaitu MAP kurang dari $60 \mathrm{mmHg}$ saat induksi anestesi atau MAP lebih dari $110 \mathrm{mmHg}$ saat intubasi sampai 5 menit setelah intubasi, 
Tabel 1 Karakteristik Subjek Penelitian dan Data Awal Sebelum Induksi Anestesi

\begin{tabular}{|c|c|c|c|}
\hline \multirow{3}{*}{ Variabel } & \multicolumn{2}{|c|}{ Teknik Intubasi } & \multirow{3}{*}{ Nilai p } \\
\hline & $\begin{array}{l}\text { Laringoskopi } \\
\text { Macintosh }\end{array}$ & $\begin{array}{c}\text { Laringoskopi } \\
\text { McCoy }\end{array}$ & \\
\hline & $\mathrm{n}=\mathbf{2 0}$ & $\mathbf{n}=\mathbf{2 0}$ & \\
\hline Usia (tahun) & & & 1,000 \\
\hline Mean \pm Std & $27,75 \pm 7,731$ & $27,75 \pm 7,906$ & \\
\hline Median & 26,50 & 30,50 & \\
\hline Range (min.-maks.) & $18,00-43,00$ & $18,00-43,00$ & \\
\hline Jenis kelamin & & & 1,000 \\
\hline Laki-laki & 9 & 9 & \\
\hline Perempuan & 11 & 11 & \\
\hline Tinggi badan $(\mathrm{cm})$ & & & 0,527 \\
\hline Mean \pm Std & $160,60 \pm 6,201$ & $161,95 \pm 7,126$ & \\
\hline Median & 161,00 & 164,50 & \\
\hline Range (min.-maks.) & $148,00-168,00$ & $147,00-172,00$ & \\
\hline Berat badan (kg) & & & 0,704 \\
\hline Mean \pm Std & $61,10 \pm 7,411$ & $62,05 \pm 8,236$ & \\
\hline Median & 61,00 & 61,00 & \\
\hline Range (min.-maks.) & $48,00-75,00$ & $45,00-76,00$ & \\
\hline BMI & & & 0,859 \\
\hline Mean \pm Std & $23,55 \pm 1,791$ & $23,65 \pm 1,755$ & \\
\hline Median & 23,00 & 24,00 & \\
\hline Range (min.-maks.) & $21,00-27,00$ & $21,00-27,00$ & \\
\hline Mallampati & & & 0,799 \\
\hline 1 & 7 & 6 & \\
\hline 2 & 13 & 14 & \\
\hline \multicolumn{4}{|l|}{ Laju nadi (x/menit) } \\
\hline Mean \pm Std & $88,05 \pm 5,195$ & $88,55 \pm 5,052$ & 0,759 \\
\hline Median & 87,00 & 88,50 & \\
\hline Range (min.-maks.) & $80,00-98,00$ & $78,00-98,00$ & \\
\hline MAP (mmHg) & & & 0,364 \\
\hline Mean \pm Std & $92,85 \pm 3,030$ & $93,70 \pm 2,811$ & \\
\hline Median & 92,00 & 94,00 & \\
\hline Range (min.-maks.) & $87,00-98,00$ & $90,00-99,00$ & \\
\hline
\end{tabular}

Keterangan: untuk data numerik nilai p diuji dengan uji T tidak berpasangan apabila data berdsitribusi normal dengan alternatif Uji Mann Whitney apabila data tidak berdistribusi normal. Data kategorik nilai p dihitung berdasar atas uji chi-square dengan alternatif Uji Kolmogorov Smirnov dan Exact Fisher apabila syarat dari chi-square tidak terpenuhi. Nilai kemaknaan berdasar atas nilai $p<0,05$. Tanda* menunjukkan nilai $p<0,05$ artinya signifkan secara statistik 
intubasi lebih dari satu kali percobaan, dan backward upward and rightward pressure (BURP) manuver saat intubasi.

Penentuan besar sampel itu dilaksanakan berdasar atas perhitungan statistik dengan menetapkan taraf kepercayaan 95\% dan kuasa uji (powertest) 90\%. Berdasar atas perhitungan didapatkan jumlah sampel untuk tiap-tiap kelompok adalah 20 orang. Pengambilan sampel dilakukan secara consecutive sampling. Randomisasi subjek penelitian dilaksanakan menggunakan permutasi blok.

Setelah mendapatkan persetujuan dari Komite Etik Penelitian Kesehatan Fakultas Kedokteran Universitas Padjadjaran RSUP Dr. Hasan Sadikin Bandung, peserta penelitian yang memenuhi kriteria inklusi dan tidak termasuk kriteria eksklusi dibagi menjadi dua kelompok. Kelompok MI dengan Macintosh dan kelompok MC dengan McCoy. Pengukuran tekanan darah diukur pada saat sebelum induksi anestesi, sebelum dilakukan intubasi, menit ke-1, menit ke-2,5 serta menit ke-5 setelah intubasi menggunakan tensimeter digital noninvasif (Omron ${ }^{\circledR}$ HEM8712). Pasien diinduksi menggunakan fentanil dosis $2 \mu \mathrm{g} /$ $\mathrm{kgBB}$, propofol $2 \mathrm{mg} / \mathrm{kgBB}$. Setelah pasien tertidur dibuka anestesi inhalasi sevofluran 3 vol\%, kemudian diberikan pelumpuh otot atrakurium 0,5 mg/kgBB. Setelah 3 menit dari pemberian pelumpuh otot dilakukan intubasi laringoskopi direk.

Analisis statistik menggunakan uji $t$ tidak berpasangan jika data berdistribusi normal dan Uji Mann-Whitney jika data berdistribusi tidak normal. Kemaknaan hasil uji statistik ditentukan berdasar atas nilai $\mathrm{p}<0,05$. Data diolah dengan program statistical product and service solution (SPSS) versi 24.0 for windows.

Tabel 2 Perbandingan Laju Nadi pada Kedua Kelompok

\begin{tabular}{|c|c|c|c|}
\hline \multirow{3}{*}{ Laju Nadi } & \multicolumn{2}{|c|}{ Laringoskopi Intubasi } & \multirow{3}{*}{ Nilai p } \\
\hline & $\begin{array}{l}\text { Laringoskop } \\
\text { Macintosh }\end{array}$ & $\begin{array}{c}\text { Laringoskop } \\
\text { McCoy }\end{array}$ & \\
\hline & $\mathbf{n}=\mathbf{2 0}$ & $n=20$ & \\
\hline Sebelum intubasi (X/menit) & & & 0,925 \\
\hline Mean \pm Std & $62,95 \pm 5,145$ & $62,95 \pm 3,531$ & \\
\hline Median & 63,00 & 64,00 & \\
\hline Range (min.-maks.) & $55,00-75,00$ & $56,00-67,00$ & \\
\hline 1 menit setelah intubasi (X/menit) & & & $0,0001^{*}$ \\
\hline Mean \pm Std & $111,55 \pm 10,450$ & $87,25 \pm 8,515$ & \\
\hline Median & 113,00 & 89,50 & \\
\hline Range (min.-maks.) & $90,00-132,00$ & $72,00-98,00$ & \\
\hline 2,5 menit setelah intubasi $(\mathrm{X} /$ menit $)$ & & & $0,0001^{*}$ \\
\hline Mean \pm Std & $111,45 \pm 7,639$ & $89,50 \pm 5,114$ & \\
\hline Median & 112,00 & 88,50 & \\
\hline Range (min.-maks.) & $96,00-124,00$ & $80,00-100,00$ & \\
\hline 5 menit setelah intubasi (X/menit) & & & $0,0001^{*}$ \\
\hline Mean \pm Std & $95,65 \pm 5,806$ & $82,55 \pm 3,561$ & \\
\hline Median & 96,00 & 82,50 & \\
\hline Range (min.-maks.) & $88,00-108,00$ & $74,00-88,00$ & \\
\hline
\end{tabular}


Tabel 3 Perbandingan Persentase Peningkatan Laju Nadi pada Kedua Kelompok

\begin{tabular}{|c|c|c|c|}
\hline \multirow[b]{2}{*}{ Presentase Peningkatan Laju Nadi } & \multicolumn{2}{|c|}{ Laringoskopi Intubasi } & \multirow[b]{2}{*}{ Nilai p } \\
\hline & $\begin{array}{c}\begin{array}{c}\text { Laringoskop Macintosh } \\
\mathrm{n}=\mathbf{2 0}\end{array} \\
\end{array}$ & $\begin{array}{c}\text { Laringoskop McCoy } \\
\mathrm{n}=\mathbf{2 0}\end{array}$ & \\
\hline 1 menit setelah intubasi (\%) & & & $0,0001^{*}$ \\
\hline Mean \pm Std & $78,23 \pm 21,314$ & $38,89 \pm 14,504$ & \\
\hline 2,5 menit setelah intubasi (\%) & & & $0,0001^{*}$ \\
\hline Mean \pm Std & $78,22 \pm 19,685$ & $42,62 \pm 11,571$ & \\
\hline 5 menit setelah intubasi (\%) & & & $0,0001^{*}$ \\
\hline Mean \pm Std & $53,10 \pm 17,546$ & $31,45 \pm 8,110$ & \\
\hline
\end{tabular}

Keterangan: untuk data numerik nilai diuji dengan uji T tidak berpasangan apabila data berdsitribusi normal dengan alternatif Uji Mann Whitney apabila data tidak berdistribusi normal. Nilai kemaknaan berdasar atas nilai $\mathrm{p}<0,05$

\section{Hasil}

Karakterisitik subjek penelitian berdasar atas usia, jenis kelamin, tinggi badan, berat badan, BMI, mallampati, laju nadi, dan MAP sebelum induksi anestesi pada kedua kelompok tidak terdapat perbedaan bermakna secara statistik ( $>0$,05; Tabel 1).

Tidak ada perbedaan bermakna secara statistik laju nadi pada kedua kelompok sesaat sebelum intubasi $(\mathrm{p}>0,05)$. Laju nadi 1 menit setelah intubasi, 2,5 menit setelah intubasi,

Tabel 4 Perbandingan Perubahan MAP pada Kedua Kelompok

\begin{tabular}{|c|c|c|c|}
\hline \multirow[b]{2}{*}{ MAP } & \multicolumn{2}{|c|}{ Laringoskopi Intubasi } & \multirow[b]{2}{*}{ Nilai p } \\
\hline & $\begin{array}{l}\text { Laringoskop Macintosh } \\
\mathrm{n}=\mathbf{2 0}\end{array}$ & $\begin{array}{l}\text { Laringoskop McCoy } \\
\qquad \mathrm{n}=20\end{array}$ & \\
\hline Sesaat sebelum intubasi (mmHg) & & & 0,142 \\
\hline Mean \pm Std & $61,40 \pm 1,957$ & $62,05 \pm 1,932$ & \\
\hline Median & 61,00 & 61,50 & \\
\hline Range (min.-maks.) & $60,00-67,00$ & $60,00-67,00$ & \\
\hline 1 menit setelah intubasi (mmHg) & & & $0,0001^{*}$ \\
\hline Mean \pm Std & $85,40 \pm 6,516$ & $71,45 \pm 6,295$ & \\
\hline Median & 84,00 & 70,00 & \\
\hline Range (min.-maks.) & $74,00-96,00$ & $64,00-88,00$ & \\
\hline 2,5 menit setelah intubasi $(\mathrm{mmHg})$ & & & $0,0001^{*}$ \\
\hline Mean \pm Std & $85,05 \pm 8,127$ & $73,85 \pm 6,106$ & \\
\hline Median & 83,00 & 73,00 & \\
\hline Range (min.-maks.) & $75,00-108,00$ & $66,00-90,00$ & \\
\hline 5 menit setelah intubasi (mmHg) & & & $0,0001^{*}$ \\
\hline Mean \pm Std & $81,65 \pm 7,285$ & $72,30 \pm 5,016$ & \\
\hline Median & 82,00 & 71,00 & \\
\hline Range (min.-maks.) & $70,00-102,00$ & $66,00-85,00$ & \\
\hline
\end{tabular}

Keterangan: untuk data numerik nilai p diuji dengan uji T tidak berpasangan. Nilai kemaknaan berdasar atas nilai $\mathrm{p}<0,05$. Tanda *menunjukkan nilai $\mathrm{p}<0,05$ artinya signifkan atau bermakna secara statistik 
Tabel 5 Perbandingan Persentase Peningkatan MAP antara Kedua Kelompok

\begin{tabular}{|c|c|c|c|}
\hline \multirow[b]{2}{*}{ Presentase Peningkatan MAP } & \multicolumn{2}{|c|}{ Laringoskopi Intubasi } & \multirow[b]{2}{*}{ Nilai p } \\
\hline & $\begin{array}{l}\text { Laringoskop Macintosh } \\
\qquad \mathbf{n = 2 0}\end{array}$ & $\begin{array}{c}\text { Laringoskop McCoy } \\
\mathbf{n = 2 0}\end{array}$ & \\
\hline 1 menit setelah intubasi (\%) & & & $0,0001^{*}$ \\
\hline Mean \pm Std & $39,09 \pm 9,885$ & $15,16 \pm 9,734$ & \\
\hline 2,5 menit setelah intubasi (\%) & & & $0,0001^{*}$ \\
\hline Mean \pm Std & $38,34 \pm 9,856$ & $18,99 \pm 8,700$ & \\
\hline 5 menit setelah intubasi (\%) & & & $0,0001^{*}$ \\
\hline Mean \pm Std & $32,85 \pm 9,128$ & $16,49 \pm 6,731$ & \\
\hline
\end{tabular}

Keterangan: untuk data numerik nilai diuji dengan uji T tidak berpasangan apabila data berdsitribusi normal dengan alternatif Uji Mann Whitney apabila data tidak berdistribusi normal. Nilai kemaknaan berdasar atas nilai $\mathrm{p}<0,05$

dan 5 menit setelah intubasi lebih rendah pada kelompok McCoy dibanding dengan kelompok Macintosh, dengan perbedaan yang signifikan ( $\mathrm{p}<0,05$; Tabel 2).

Persentase peningkatan laju nadi pada Macintosh lebih besar bila dibanding dengan McCoy pada menit ke-1 $(78,23 \pm 21,314 \%$ vs $38,89 \pm 14,504 \%)$, pada menit ke-2,5 $(78,22 \pm 19,685 \% \quad$ vs $42,62 \pm 11,571 \%)$, dan pada menit ke-5 $(53,10 \pm 17,546 \%$ vs $31,45 \pm 8,110 \%$ ) dengan perbedaan yang singnifikan ( $\mathrm{p}<0,05$; Tabel 3$)$.

Tidak ada perbedaan signifikan secara statistik MAP antara kedua kelompok sesaat sebelum intubasi $(p>0,05)$. Nilai MAP 1 menit setelah intubasi, 2,5 menit setelah intubasi, dan 5 menit setelah intubasi lebih tinggi pada kelompok Macintosh dibanding dengan kelompok McCoy, dengan perbedaan signifikan $(\mathrm{p}<0,05$; Tabel 4).

Persentase peningkatan MAP saat 1 menit setelah intubasi, 2,5 menit setelah intubasi, dan 5 menit setelah intubasi lebih tinggi pada kelompok Macintosh dibanding dengan kelompok McCoy dengan perbedaan signifikan $(\mathrm{p}<0,05$; Tabel 5).

\section{Pembahasan}

Karakterisitik subjek penelitian berdasar atas laju nadi dan MAP sebelum induksi anestesi pada kedua kelompok tidak terdapat perbedaan bermakna sehingga dianggap homogen dan layak untuk dibandingkan.

Pada penelitian ini, laringoskop bilah McCoy dapat mengurangi peningkatan laju nadi dibanding bilah Macintosh setelah laringoskopi intubasi pada menit ke-1, menit ke-2,5, dan menit ke-5 secara signifikan. Respons hemodinamik akibat stimulus mekanik pada saluran napas atas paling besar terjadi pada daerah epifaring dan laring karena banyak reseptor eferen simpatis di daerah tersebut. Stimulus ini terjadi akibat rangsang pada saraf glossopharyngeal yang terletak di permukaan anterior glotis dan saraf vagus pada bagian bawah posterior epiglotis sampai saluran napas bagian bawah. Hal ini menjelaskan mengapa pemilihan bilah laringoskop tersebut dapat memengaruhi respons hemodinamik pascalaringoskopi intubasi. Dari beberapa penelitian dinyatakan bahwa laringoskop bilah McCoy dan Miller menghasilkan peningkatan laju nadi yang lebih rendah saat laringoskopi dibanding dengan bilah Macintosh karena kontak yang minimal pada daerah tersebut saat laringoksopi. ${ }^{1,3,12}$

Pada penelitian ini, MAP setelah intubasi pada menit ke-1, menit ke-2,5, dan menit ke-5 lebih rendah pada kelompok McCoy dibanding dengan Macintosh dan berbeda signifikan. Dari penelitian sebelumnya dijelaskan bahwa laringoskopi pada pasien dengan posisi netral menggunakan laringoskop bilah McCoy dapat meningkatkan derajat Cormack and Lehane 
hingga 2 kali hanya dengan mengelevasikan ujung tip dari bilah McCoy tanpa melakukan pengangkatan paksa dari bilah laringoskop. ${ }^{1}$ Backward upward and rightward pressure (BURP) manuver serta pergerakan leher dan kepala juga minimal dibanding dengan bilah Macintosh. Hal ini menjelaskan sedikitnya manipulasi jalan napas atas saat laringoskopi mempergunakan McCoy sehingga lonjakan hemodinamik yang terjadi pascalaringoskopi juga minimal. ${ }^{1,3,15}$

Pada penelitian ini terjadi peningkatan laju nadi dan MAP pada kedua kelompok setelah intubasi. Ternyata perbedaan persentase peningkatan laju nadi dan MAP menit ke-1, menit ke-2,5, dan menit ke-5 setelah intubasi kelompok McCoy lebih kecil dibanding dengan Macintosh dan berbeda signifikan. Hasil ini sejalan dengan penelitian yang pernah dilakukan sebelumnya yang membandingkan laringoskop bilah McCoy dengan Macintosh pada pasien diprediksi jalan napas mudah dan sulit. Didapati peningkatan laju nadi dan tekanan darah lebih rendah pada kelompok McCoy baik pada pasien dengan prediksi jalan napas mudah dan sulit dibanding dengan Macintosh secara signifikan. ${ }^{4}$

Laringoskop Macintosh itu adalah jenis laringoskop yang paling dikenal dan banyak digunakan, tingkat kesuksesan dengan bilah ini tinggi, dan penggunannya juga relatif mudah dipelajari. ${ }^{4}$ Seiring perkembangan teknologi kedokteran pada awal 1990-an terdapat jenis laringoskop baru modifikasi dari laringoskop bilah Macintosh, yaitu laringoskop bilah McCoy. ${ }^{13}$ Kekurangan laringoskop bilah Macintosh adalah lengkungannya yang dapat menutup visualisasi glotis dan jalur intubasi pada kondisi jalan napas sulit., ${ }^{3,4}$ Dasar lidah juga dapat tertekan ke arah distal dan terjadi penekanan paksa pada epiglotis dan valekula ke atas serta terjadi pergeseran epiglotis ke arah posterior untuk visualisasi pita suara pada saat laringoskopi intubasi. Manuver ini menimbulkan respons lonjakan hemodinamik yang lebih besar dibanding dengan McCoy.,3

Respons hemodinamik yang terjadi saat laringoskopi intubasi berlangsung singkat. Konsekuensi yang ditimbulkan pada individu sehat minimal.,15 Komplikasi serius dapat terjadi pada individu dengan penyakit penyerta seperti penyakit jantung koroner, hipertensi, aneurisma pembuluh darah, dan asma bronkial, serta pasien dengan peningkatan tekanan intrakranial. ${ }^{3,14}$ Penelitian lain yang pernah dilakukan di Turki meneliti tentang peranan neuroendokrin terhadap perubahan hemodinamik saat laringoskopi dan intubasi. Penelitian ini menganalisis kadar epinefrin, norepinefrin dan vasopressin plasma saat sebelum induksi, sebelum intubasi, dan setelah intubasi. Penurunan kadar epinefrin terjadi setelah pemberian obat anestesi saat induksi, kemudian didapatkan peningkatan yang signifikan kadar norepinefrin dan epinefrin plasma saat setelah intubasi. Penurunan kadarnya dalam plasma mendekati nilai awal terjadi setelah lima menit tindakan intubasi. ${ }^{16}$

Saat ini alat-alat bantu jalan napas banyak mengalami evolusi. Alat dibuat tidak hanya untuk memfasilitasi laringoskopi intubasi, namun juga dirancang untuk memudahkan pada skenerio intubasi yang sulit dan juga untuk mengurangi rangsang simpatis saat laringoskopi intubasi. ${ }^{5}$ Respons lonjakan hemodinamik yang minimal saat laringoskopi dengan McCoy memiliki manfaat klinis, seperti dapat mengurangi kebutuhan opioid untuk dapat menumpulkan respons simpatis sehingga dapat mengurangi efek samping obat tersebut. $^{8}$

Penelitian lainnya pada 160 pasien bedah saraf yang dilaksanakan intubasi dengan menggunakan McCoy menghasilkan perubahan yang ternayata lebih rendah pada peningkatan laju nadi dan tekanan darah dibanding dengan Macintosh ketika fentanil tidak digunakan saat induksi. Dari beberapa penelitian juga ada yang menyimpulkan bahwa tidak mendapatkan perbedaan peningkatan hemodinamik yang signifikan saat laringoskopi intubasi mempergunakan McCoy dan Macintosh jika kedua kelompok diberikan fentanil sebelum intubasi. ${ }^{8}$

Keterbatasan penelitian adalah penelitian ini tidak dapat double blind karena yang melakukan intubasi mengetahui alat apa yang dilaksanakan sehingga dapat menyebabkan 
bias hasil penelitian. Keterbatasan kedua adalah tidak dilaksanakan pengukuran kedalaman anestesi dan derajat relaksasi otot karena kedalaman anestesi dan relaksasi otot dapat memengaruhi respons simpatis dari tindakan laringoskopi. Keterbatasan ketiga adalah tidak mempergunakan pemantauan tekanan darah invasif yang dapat mengetahui perubahan tekanan darah setiap detiknya.

\section{Simpulan}

Peningkatan laju nadi dan MAP saat laringoskopi direk dengan laringoskop bilah McCoy lebih minimal bila dibanding dengan Macintosh pada pasien yang menjalani operasi dengan anestesi umum.

\section{Daftar Pustaka}

1. Nadkarni M, Patel RD, Behera P, Walzade P. Comparison of macintosh, mccoy and miller laryngoscope blades for intubation - a prospective randomised study. J Dend Med Sci. 2016;15(8):85-91.

2. Paul A, Nathroy A. Comparison of hemodynamic changes during laryngoscopy with mccoy and macintosh laryngoscopes. J Health Res Rev. 2017;4(1):35-9.

3. Sachidananda R, Umesh G, Shaikh SI. A review of hamodynamic response to the use of different types of laryngoscopes. Anaesth PainIntensCare.2016;20(2):1-15.

4. Arshad Z, Abbas H, Bogra J, Sulekha S. Comparison of laryngoscope view and hemodynamic changes with flexitip McCoy and Macintosh laryngoscope blade in predicted easy and difficult airway. Open J Anesthesiol. 2013;3:278-82.

5. Kamawed AK, Sharma V, Kamewd S, Popli V. Haemodynamic response to endotracheal intubation: direct versus video laringoscopy. Int J Res Med Sci. 2016;4(12):5196-200.

6. Tempe DK, Chaudhary K, Diwakar A, Datt V, Virmanni S, Tomar AS, dkk. Comparison of hemodynamic responses to laryngoscopy and intubation with truview pcd, mcgrath and macintosh laryngoscope in patients undergoing coronar artery bypass grafting: a randomized prospective study. Ann Card Anaesth. 2016:19:68-75.

7. Arora S, Kulkarni A, Bhargava AK. Attenuetion of hemodynamic response to laryngoscopy and orotracheal intubation using intravenous clonidine. J Anesthesiol Clin Phar. 2015;31(1):110-4.

8. Haidry M, Khan F. Comparison of hemodynamic to tracheal intubation with macintosh and mccoy laryngoscope. J Anesthesiol Clin Phar. 2013;29(2):196-9.

9. Marsaban AH, Heriwardito A, Yuda IG. Cardiovascular response and backward, upward, right push maneuver during laryngoscopy: comparison between CMAC videolaryngoscopy and conventional Macintosh. Med J Indos. 2017;26(2):116-21.

10. Gill N, Prrohit S, Kalra P, Khare A. Comparison of hemodynamic responses to intubation: flexible fiberoptic bronchoscope versus McCoy laryngoscope in presence of rigid cervical collar simulating cervical immobilization for traumatic cervical spine. Anesth Essays Res. 2015;9(3):337-42.

11. Kumar A, Seth A, Prakash S, Deganwa M, Gogja A. Attenuation hemodynamic response to laryngoscopy and tracheal intubation with fentanyl, lignocaine, and a combination of both: randomized controlled trial. Anesth Essays Res. 2016;10(3):661-6.

12. Gotiwale K, Lele S, Setiya S. Stress response to laryngoscopy and ease of intubation: comparison between Macintosh and (levering) Mccoy type laryngoscope. Int J Res Med Sci. 2016;4(8):3141-5.

13. Vaswani J, Malik C, Bhalerro Y, Vyas V, Chedda K. Stress response to laryngoscopy: comparison between Machintosh and Mccoy type laryngoscope blade. J Dend Med Sci. 2017;16(1):76-80.

14. Yallapragada SV, Vidadala KS, Vemuri NN, Shaik MS. Comparison of efficacy of dexmedemotomidine with that of the esmolol in attenuating laryngoscopic 
and intubation response after rapid sequence induction. Anesth Essay Res. 2014;8(3):383-7.

15. Yoo KY, Lee JU, Kim HS, Im WM. Hemodynamic and catecholamine responses to laryngoscopy and tracheal intubation in patients with complete spinal cord injuries. Anesthesiology.
2001;95(3):647-51.

16. Kayhan Z, Aldemir D, Mutlu H, Ogus E. Which is responsible for the haemodynamic response due to laryngoscopy and endotracheal intubation? catecholamines, vasopressin or angiotensin?. Eur J Anesthesiol. 2005;22(10):780-5. 